\title{
Research Dryer for Drying Agricultural Products
}

\author{
Norkulova $\mathrm{K}^{1 *}$, Iskandarov $\mathrm{Z}^{2}$, Safarov $\mathrm{J}^{1}$ and Jumayev $\mathbf{B}^{1}$ \\ ${ }^{1}$ Tashkent State Technical University, Uzbekistan \\ ${ }^{2}$ Tashkent State Agrar University, Uzbekistan
}

\begin{abstract}
The paper proposes a structural model of the solar dryer comprising a closed housing having a rectangular cross section, mounted inside it on the traction chain conveyor mesh trays for a product, drive, fan, electric heater and an annular heat regenerator. The body is covered with a translucent shell of sheet organic glass with a certain gap and forms a loop recirculation of air in the doorway between the cameras mounted additional regenerator shell and tube filled with heat storage material. Gelio drying systems equipped with butterfly valves, pipes and air ducts providing capture solar radiation and heat recovery junk coolant.
\end{abstract}

Keywords: Drying installations; Cradle of conveyor; Drying; Agricultural products; Helio drying

\section{Introduction}

Uzbekistan annually produces more than 5 million tons of fruits and vegetables. However, a large number of lost on the field, in the collection, transportation and storage. Sometimes the loss is about $40 \%$. Questions reduce the loss of raw materials and products, saving valuable components of fruits, issue of import-substituting and export-oriented products, as well as improve transport efficiency requires the development of processing industries, particularly the processes and systems for drying. Dried fruit and raisin production is based mainly on natural air-drying sun. Before drying, the product is fumigated blanched and sulfur dioxide in alkali. Applied chemicals environmentally unclean, but still involves blanching and loss of dry matter. Moreover, due to the effects of the environment and direct sunlight with a natural air solar drying of agricultural products. The quality of the final product can be reduced, and therefore requires additional processing factory.

Therefore, along with the current trend in the art of improving infrared structures known sources of infrared radiation it is necessary to develop new designs of these sources, particularly the low temperature radiator in the spectrum range using new heat sources body with mixed emitters emitting surface [1]

Scientists in the Tashkent State Technical University have been designed and infrared vacuum unit and drying of agricultural technology. These technology $(22 \mathrm{~kW})$ for a short time (15-160 minutes) at low temperatures $\left(40-70^{\circ} \mathrm{C}\right)$ dry agricultural products with different densities, structure and size of a maximum preservation of trace elements (90\%) [2].

\section{Objects and Methods}

The use of solar drying plants, although it became a definite step to address these shortcomings, but all the same dependence on the weather conditions and the lack of productivity hinders their widespread introduction.

Developed by scientists and Tashkent state technical university and Tashkent state agrar university dryers' structures for drying agricultural products are divided into fuel and solar. Each of them has its advantages and disadvantages. For example, the benefits of fuel dryers are high performance and the ability to transfer on an industrial basis. The disadvantages include: energy consumption, low efficiency of solar energy utilization and waste of drying agent and the lack of maintenance of the set temperature by regulating the power of the heat source. The advantages of solar drying plants are such as: saving fuel and energy resources, improving the environmental performance of production. The disadvantages include the following: dependence on weather conditions, longer duration of the drying process, the low efficiency of the generated solar power and waste heat, reducing efficiency in the absence of sunlight (at night and cloudy weather). Known helio dryer, comprising the chamber, drying the cassette loading and unloading hatch, valve device for discharging air and heating unit and translucent skin covering the camera. On the outer side camera mounted at least two helical guides and made in the top of the annular groove chamber in communication with the recirculation loop [3].

The purpose of this development is to reduce the helium dryer energy. However, the operation showed that manufacturing spiral swirlers associated with excessive consumption of steel sheet, it will reveal the unreliability and translucent shell, and she could not stand the heat load ring and came into disrepair. In addition, it is not oriented to the cardinal points due to the fixed structure, and in the best case, the absorbent side of the camera working at $50-60 \%$.

Helio is improved dryer design that differs from the previous in that the chamber is suspended on a bearing support for rotation about a vertical axis by performing at the top of the slots flare outwardly with tangential and discharge pipe introduced into the chamber and mounted coaxially. Here, the effect of "Segner" was applied [4].

However, performance testing has shown that although the camera is mounted slidably and increases heat-retaining capacity, but with an increase in plant capacity effect "Segner" does not give the proper rotation of the camera by increasing the tonnage of drying cartridges.

In addition, the increase in height helio dryer fraught rollover installation due to possible wind loads and gusts.

*Corresonding author: Norkulova $\mathrm{K}$, doctor technical seince, professor Tashkent state technicak university, Uzbekistan, Tel: +99871 27-19-32; E-mail: jasursafarov@mail.ru

Received June 09, 2016; Accepted June 27, 2016; Published July 04, 2016

Citation: Norkulova K, Iskandarov Z, Safarov J, Jumayev B (2016) Research Dryer for Drying Agricultural Products. J Food Ind Microbiol 2: 111. doi:10.4172/25724134.1000111

Copyright: (c) 2016 Norkulova K, et al. This is an open-access article distributed under the terms of the Creative Commons Attribution License, which permits unrestricted use, distribution, and reproduction in any medium, provided the original author and source are credited. 
The third option is an improvement dryer helio [5]. On a design it is identical to the first two dryers, except embodiments on spiral swirl ring. However, it is not without the same basic drawbacks of their predecessors. In addition, multiple studies of uneven drying of the product were found in the lower and upper cassette chamber. As you move up, the drying agent is saturated with vapor of evaporated moisture, and on the upper cassette condensate deposition is observed in some fruits.

Iskandarov [6] proposed a modernized drying plant for drying, consisting of two vertical cameras mounted on the T-shaped support, and it provided for the use of regenerative heat exchangers for heat economy.

The author the above operation followed the path of the mating pool their early inventions, creating a more stable structure for the installation, but the former disadvantages remain unsolved.

\section{Results and Discussion}

The proposed installation ensures uniformity of product drying in a stable convection mode, using solar energy and a partial regeneration of the exhaust waste heat. To achieve the above positive effect in the upgraded dryer is provided with two separate vertical cameras mounted inside their load-bearing reticulate pallets, drive, loading and unloading hatch connections input and removal of drying agent, fan, electric heater, a regenerator. This camera is mounted on top of the swirlers and translucent shell, forming the outer contour of the recirculation of the drying agent, and the top of the camera are provided sipes. Vertical camera connected at the top and bottom of the horizontal channels, forming a sealed closed housing of rectangular cross section, on the side surfaces of which are installed in vertical rows corrugated swirlers. Over swirlers fixed translucent shell made of organic glass, and in the doorway between the vertical portions of the regenerator chambers built shell and tube heat annulus is filled with heat-retaining substance. The slots are communicated at the top with a butterfly valve through the recirculation loop of the drying agent and inlet branch pipe tube bundle heat regenerator and the outlet from the last air channel air supply system. As hyphen heat accumulating material can be used, hydrated - monosodium phosphate and $10 \%$ aqueous $\mathrm{NaCl}$.

Helio dryer of cradle-type conveyor comprises a hermetic housing 1 closed rectangular section, consists of two vertical chambers 2 are connected at the top and bottom of the horizontal channels 3 . The body 1 is made of blackened steel plate by welding. At the top of the casing 1 is placed drive, comprising an electric motor 4 , the worm gear 5 , two pairs of gears 6,7 and the driven shaft that transmits rotation of the traction chain drive sprockets 8,9 . In the last step a certain calculated fixed on earrings 10 load-bearing reticulate trays 11 . On the external side surfaces of the walls 12 vertically mounted camera 2 in Figure 1. The last rows of turbulators made of corrugated steel sheet and also blackened with a mixture of "black nickel" for better absorption of solar radiation. Over 13 fixed swirlers 14 translucent shell made of organic glass. The opening between the vertical portions of cameras 2 is built with a tube bundle regenerator 15 , the upper 16 and lower plenum 17. The intertubular space of 15 is filled with a tube bundle regenerator heat storage material 18 . The upper and lower zones of the external recirculation loop 19 are butterfly valves 20 , which respectively communicate with the upper and lower nozzles 21 of the regenerator 15. On the ceiling portion of the housing 1 are provided slit slit 22 for exit of air in a recirculation loop 19. On the left side wall of the chamber 2 is a hyphen horizontal opening hatch - hole 23 . Helio dryer is equipped with a fan 24 , electric heater 25 , regenerator 26 , a ring

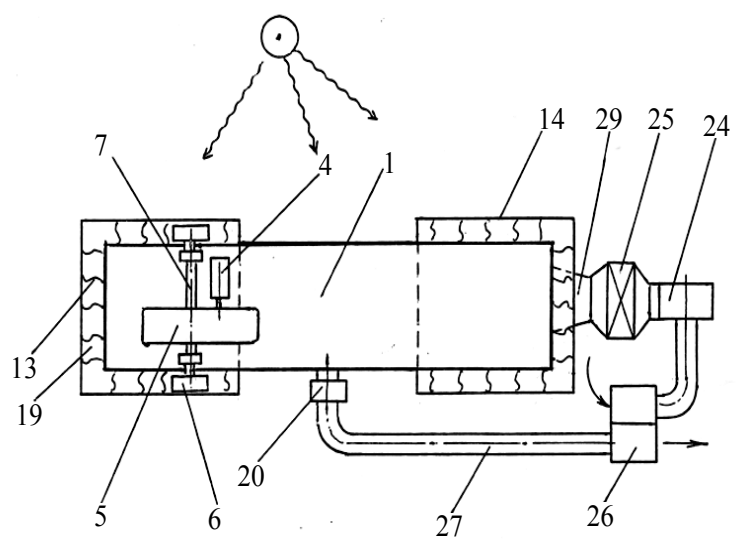

Figure 1: General view of the helio-drying of cradle-type conveyor.

filled with granular selikogelem and external air channel 27. The two branches of the circuit 9 are connected to the load-bearing rods 28 .

Consider the work of helio dryer of cradle-type conveyor. After starting the drive motor is turned 4 , worm gear 5 , two pairs of gears 6,7 and the driven shaft that transmits rotation of the traction chain drive sprockets 8,9 . Thus there is a chain of moving around a closed circuit of the housing 1 . Through the open manhole 24 at the approach of the next load-bearing mesh tray 11 suspended on earrings 10 to a chain transmission 9 pallets laid a dried product: - For example, grapes, apricots, etc. After loading all trays 11, closing the manhole 23 include drive continuous operation, and the fan 24 , the electric heater 25 and the annular regenerator 26.

In this case, the heated air in the electric heater 25 through inlet 29 flows into the right camera 2 and blows laid on pallets 11 product. Due to steady convective drying process, is constantly in motion, the product gives intensive moisture and dries evenly on all pallets. As the air moves up the camera, it is saturated with moisture evaporated, and part of it flows through the slots 22 in slit re-circulation circuit 19 formed by the outer surface of the housing 1 and the translucent envelope 14. The latter is made of organic glass of $3 \mathrm{~mm}$ in view of mechanical strength and durability. Flowing around from top to bottom between the corrugated iron 13 , the air is additionally heated by direct sunlight. Note that the temperature of air heated by the sun is further improved mainly due to conductive heat transfer between the light absorbing surface of the housing 1 and the blackened swirlers 13. Next, the heated air through a butterfly valve 20 installed in the lower part of the external recirculation loop 19, enters the air duct 27 and thence into one of the chambers of the ring of regenerator 26 and removed to the outside. Suction fresh air, is partially warmed in the second annular chamber of the regenerator, enters the fan 24 and through the electric heater 25 back into the housing 1 . In the day period, with good solar radiation (about $660-820 \mathrm{~W} / \mathrm{m}^{2}$ for the latitude of the city of Tashkent in the summer and autumn months) blackened on the treated surface of the housing 1 and swirlers 13 through translucent shell 14 receives a significant amount of heat.

In the case of a tube bundle regenerator 15 embedded drying process is as follows. Functionally, the regenerator 15 is designed to operate helio drying at night. Day during insulation on the blackened surface of the regenerator receives solar radiation, which accumulates heat in the space between the tubes filled with the heat storage material 18. As such a substance may be used crystalline hyphen - monosodium phosphate 
Citation: Norkulova K, Iskandarov Z, Safarov J, Jumayev B (2016) Research Dryer for Drying Agricultural Products. J Food Ind Microbiol 2: 111. doi:10.4172/2572-4134.1000111

having good heat capacity. Under the influence of the temperature of $60-65{ }^{\circ} \mathrm{C}$, he retains heat well. In the evening or night switch 20 . The upper turning vane Then air from the external recirculation circuit 19 is supplied to the top air distribution chamber 16, passes down through the tubes is heated by heat transfer from the hot heat-accumulating material 18 and enters the bottom of the air distribution chamber 17 . The principle of operation of shell and tube heat exchangers is well known. Heated air is removed through the lower butterfly valve 20 in the air duct 27 and further, as described above. At the end of the drying fan 24 is turned off, the electric heater 25 , regenerator 26 , and the ring in the discrete-continuous mode the drive is unloaded product and lays new portions. When installing the dryer must be strictly helio orient it north-south relatively the front surface of the body, as in this positions maximum solar radiation will come.

As a result, air heated further in the recirculation circuit 19 is supplied via the duct 27, the annular regenerator 26, the fan 24 and the electric heater 25 re-enters the body 1 to dry the product. In the night period helio dryer operates only on electric heaters heat 25 and the heat accumulated in the regenerator tube bundle 15 , with or without a hyphen in the active ventilation mode, providing oscillation principle. Application of $10 \%$ - aqueous solution of common salt produces the same effect as monosodium phosphate.

\section{Conclusion}

Thus, we can conclude that the proposed helio dryer can reduce the energy consumption in the drying process to $36-40 \%$ and improve the overall efficiency dryer. The presence of chain transfer agents provide uniform drying of the product on all pallets in steady convective regime. Large metal consumption, consumption of organic glass and design complexity are covered by cost-saving energy. Such compact dryer which does not occupy a large area and easy to operate.

\section{References}

1. Norkulova KT, Safarov JE, Mamatkulov MM, Fakhrutdinov RR (2011) The patent for utility model FAP 00655. Apparatus for infrared drying.

2. Norkulova KT, Fakhrutdinov RR, Safarov JE, Mamatkulov MM (2012) Providing uniform infrared radiation drying planar material layer. Chemical Technology, Control and management 1: 16-19.

3. Baydyuk PV, Yusupov AM, Iskandarov ZS (2006) Machine and process for cutting openings in a substrate.Google patents.

4. Baydyuk PV, Yusupov AM, Iskandarov ZS (2002) Silver halide photosensitive material and image forming method therefor. Google patents.

5. Yusupov AM, Baydyuk PV, Salomov HT (2005) Sensor apparatus. Google patents

6. Iskandarov ZS (2010) Improving the efficiency of dual-chamber drying plants with heat source power control mode. Solar technology 4: 30-33. 